\title{
NEW ALUMINA SUBSTRATES FOR MICROELECTRONICS
}

\author{
K. NIWA and K. MURAKAWA \\ Fujitsu Laboratories Ltd., Kawasaki, Japan \\ (Received October 19, 1974, in final form February 25, 1975)
}

\begin{abstract}
Alumina substrates of $\mathrm{Al}_{2} \mathrm{O}_{3}-\mathrm{MgO}-\mathrm{Cr}_{2} \mathrm{O}_{3}$ give excellent surface smoothness. These were studied with respect to their green tapes, the surface finish of fired substrates, and in particular smoothness. The factors contributing to these characteristics were investigated, in particular the effect of the addition of $\mathrm{Cr}_{2} \mathrm{O}_{3}$ on surface smoothness.
\end{abstract}

\section{INTRODUCTION}

One of the important requirements for microelectronics applications is favorable surface characteristics of ceramics, particularly the surface smoothness. ${ }^{1}$ Surface roughness for instance, affects the electrical characteristics and reliability of tantalum thin film capacitors and thin film resistors.

Alumina substrates which have been used for microelectronics are still not good enough for thin film capacitors without glazing, because of their roughness and surface defects. Glazing or partial glazing treatment is necessary. This treatment will reduce the desirable properties, except for surface smoothness. It is obvious that a substrate with a completely smooth surface is most desirable for these thin film circuit elements.

It is reported ${ }^{2}$ that the smoothness of the surface of the ceramic substrate is affected by the manufacturing process, and by properties of the raw materials. The substrate surface smoothness also depends on grain structure, grain size, grain shape and substrate density In this regard, studies had been made towards obtaining smaller grains and wellordered grain structure on the surface of alumina ${ }^{3,4}$. A long period of firing at a low firing temperature, and addition of $\mathrm{MgO}$ were proposed for reducing the coarser grains, thus obtaining a smooth surface. A substrate obtained by this method will have a roughness of about $0.1 \mu \mathrm{m}$ Center Line Average (CLA). However, this surface roughness is not sufficiently low for a thin film capacitor to perform its rôle without glazing.

Therefore it was necessary to develop a new substrate with a smoother surface. From the results of several studies ${ }^{5}$ concerning addition effects on alumina sintering, it was found that addition of
$\mathrm{Cr}_{2} \mathrm{O}_{3}$ with $\mathrm{MgO}$ makes it possible to obtain higher densities at relatively low firing temperatures.

In this paper, discussion is made on the surface smoothness of a new alumina composition, $\mathrm{Al}_{2} \mathrm{O}_{3}-\mathrm{MgO}-\mathrm{Cr}_{2} \mathrm{O}_{3}$ system.

\section{EXPERIMENTAL PROCEDURES}

The alumina powder used for the new composition was of particle diameter $0.3 \mu \mathrm{m}$, and $99.7 \%$ purity. Tape casting was accomplished using polyester film as the green tape carrier. At first alumina powder was mixed with $0.25 \mathrm{wt} \%$ of $\mathrm{MgO}$ and $0.025 \mathrm{wt} \%$ of $\mathrm{Cr}_{2} \mathrm{O}_{3}$. Binder, plasticizer and solvents were then added. The powder was milled for 48 hours using a plastic mill pot and high purity (99.5\%) alumina balls. Viscosity of the slip was controlled at approximately $15 \mathrm{cP}$ by controlling evaporation of solvents in vacuum chamber.

Two methods were employed for the measurement of the surface smoothness; measurement of specular glossiness (gloss) by gloss meter ${ }^{6}$ and examination using Talysurf ${ }^{7}$.

The cast green tapes were first fired at $1300{ }^{\circ} \mathrm{C}$ in air after drying for about 24 hours to vaporize the binder, and then at $1600^{\circ} \mathrm{C}$ in hydrogen. The surface smoothness was measured at each stage, and the density of the green tapes, specific gravity of the fired substrates, microstructure and surface grain diameter were studied.

Density $\rho$ of the green tape was estimated from the following equation $(\mathrm{V}=$ volume of the green tape and $\mathrm{G}=$ weight)

$$
\rho=\mathrm{G} / \mathrm{Vx} \Phi
$$

where $\Phi$ is a constant which changes in accordance 
with the amount of binder. In this experiment, $\Phi=0.9$. Specific gravity of the substrate was measured by the well known method using water. Grain diameter of the substrate surface was calculated by the line intercept method. The microstructure was observed using a scanning electron microscope.

\section{RESULTS AND DISCUSSION}

\subsection{Unfired State}

The gloss of the surface (tape side surface) of the green tape contacting carrier film shows some variations between 60 and 70 , although there is little relationship between gloss and the density of the green tape. In the blade side surface, however, which is opposite to the carrier film, the gloss increased with the increase in density of the green tape, as shown in Figure 1. During the process of drying, if the cast slip

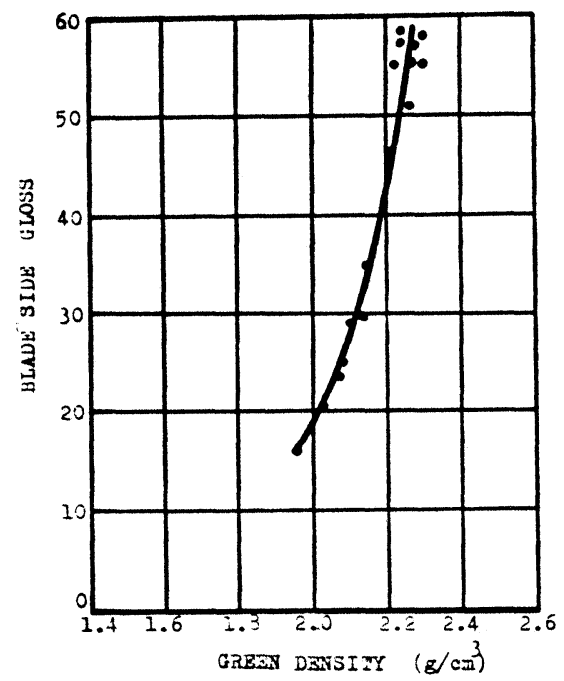

FIGURE 1 Relation between gloss of blade side and density of green tapes.

becomes densely packed, a high density green tape will be obtained, resulting possibly in improved smoothness of the blade side. On the other hand, in the case of the tape side, the surface of the green tape is in close contact with the carrier film; consequently the tape side surface will show no relationship between surface smoothness and green density. Figure 2 shows a typical example of surface roughness examined by Talysurf on the tape side. The gloss by gloss meter shows 70 on the same surface, and calculated roughness from Figure 3 is $0.05 \mu \mathrm{m}$ CLA.

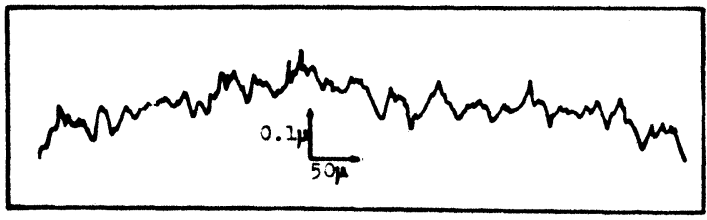

FIGURE 2 Surface roughness of green tapes examined by Talysurf; tape side.

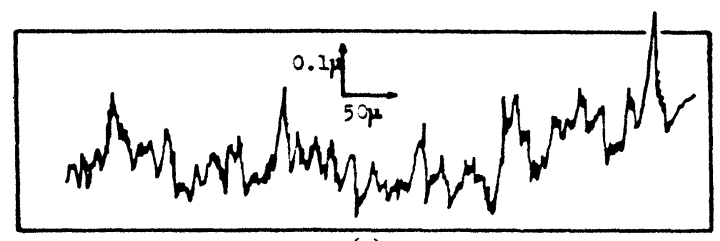

(a)

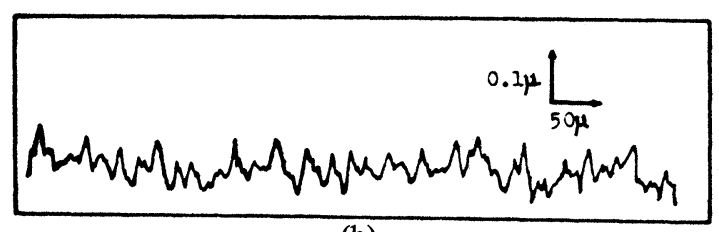

(b)

FIGURE 3 Surface roughness examined by Talysurf, 3(a) Fired at $1300^{\circ} \mathrm{C}, 2$ hours in air; tape side, 3(b) Fired at $1600^{\circ} \mathrm{C}, 2$ hours in hydrogen; tape side.

\subsection{Fired State}

The surface observation in the fired state was made on the tape side surface, which is the surface used for thin films. In the substrate fired at $1300^{\circ} \mathrm{C}$, measurement of smoothness by gloss meter was not possible, as it was found to be bent to such an extent that the reflected light from the surface was scattered. Figure 3 shows results of the Talysurf measurements of the surface of the substrates fired at $1300^{\circ} \mathrm{C}$. This substrate showed a gloss of 70 at green state, and roughness $0.05 \mu \mathrm{m}$ CLA, which changes to about $0.08 \mu \mathrm{m}$ CLA. This is possibly mainly due to the pores caused by binder vaporization during the air process. Figure 4 shows the open pores present in the surface after firing at $1300^{\circ} \mathrm{C}$. These pores disappear after firing at $1600^{\circ} \mathrm{C}$, and the fine grain structure can be observed as shown in Figure 4. In this state, roughness of less than $0.05 \mu \mathrm{m}$ CLA is obtained, as shown in Figure 3, which corresponds to that of the green state. Figure 5 shows the relationship between the gloss and the specific gravity of the substrate fired 


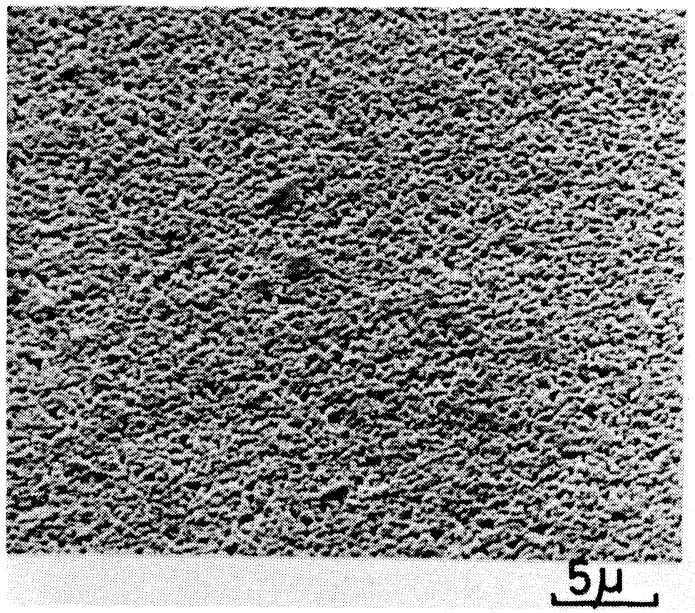

FIGURE 4 Surface microstructure of substrate; tape side, 4 (a) at $1600^{\circ} \mathrm{C}, 2$ hours in hydrogen.

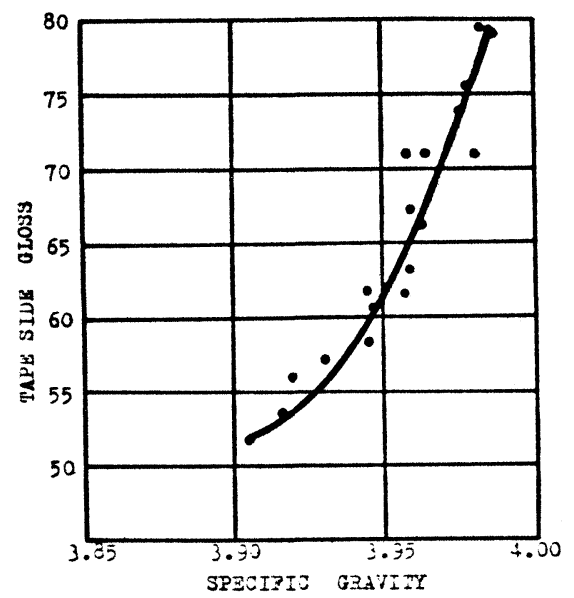

FIGURE 5 Relation between gloss of tape side and specific gravity of substrates fired at $1600^{\circ} \mathrm{C}, 2$ hours in hydrogen.

at $1600^{\circ} \mathrm{C}$ in hydrogen. A substrate which has a specific gravity greater than 3.96 shows more than 70 in gloss on the tape side surface. This result clearly suggests that the density of the fired substrate is related to the grain structure of the substrate surface, which influences strongly the smoothness of surface. As shown in Figure 6, as the surface smoothness examined by the gloss meter decreases, the wellordered grain structure of the surface deteriorates, resulting in the growth of irregular grains and pores. Straight grain boundaries and dense packing of grains

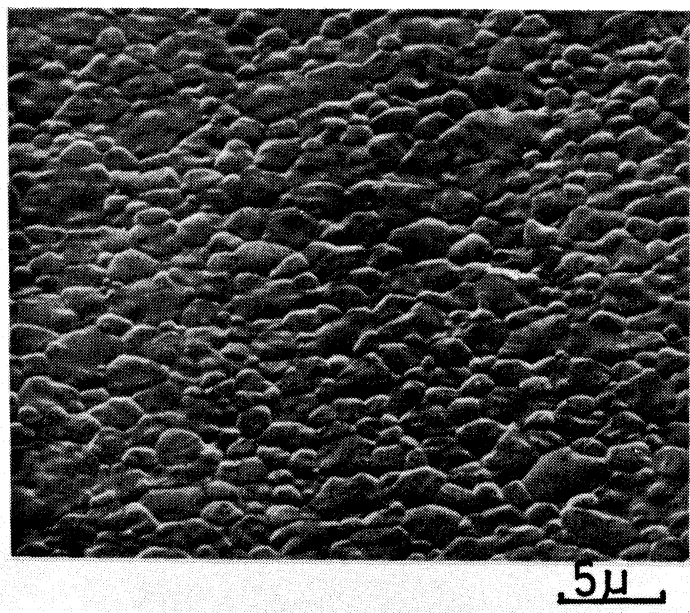

Fired at $1300^{\circ} \mathrm{C}, 2$ hours in air, $4(\mathrm{~b}) \quad$ Fired are observed in the smoother surfaces, curved grain boundaries and irregular grain shape in lower gloss (rougher) surfaces. These differences in microstructure may be caused by dissimilar grain growth mechanisms due to the different green density. It is understood that the green tapes of lower density with many pores due to binder vaporization will loose much more surface texture than those of high density. Also individual grains in the former possibly vary more in shape or size, due to the decrease in pores during firing, compared with the latter. For instance, the green tape, of less than $2.2 \mathrm{~g} / \mathrm{cm}^{2}$ density, and smoothness 60 in gloss, changes 50 to 55 after firing in hydrogen.

In accordance with the report made on $\mathrm{Al}_{2} \mathrm{O}_{3}-\mathrm{MgO}$ system alumina ${ }^{5}$, it is concluded that the grain growth is continuous with respect to the firing temperature, and the surface roughness of the substrate can be controlled by controlling firing temperature. The surface roughness, however, was limited to approximately $0.1 \mu \mathrm{m}$ CLA, and the grain arrangement is no better than that of the $\mathrm{Al}_{2} \mathrm{O}_{3}-\mathrm{MgO}-\mathrm{Cr}_{2} \mathrm{O}_{3}$ system, as shown in Figure 7.

This difference between systems suggests that the effect of $\mathrm{Cr}_{2} \mathrm{O}_{3}$ addition upon the sintering mechanism makes possible a high specific gravity at a low firing temperature. In the $\mathrm{Al}_{2} \mathrm{O}_{3}-\mathrm{MgO}-\mathrm{Cr}_{2} \mathrm{O}_{3}$ system, the substrate is coloured pink at temperatures between 1300 and $1400^{\circ} \mathrm{C}$, attributable to diffusion of $\mathrm{Cr}_{2} \mathrm{O}_{3}$. This agrees well with the report ${ }^{8}$ of Gruszka et al. This diffusion energy may accelerate the driving forth of the grain growth, which is convenient for well-ordered grain structures resulting 
(a)

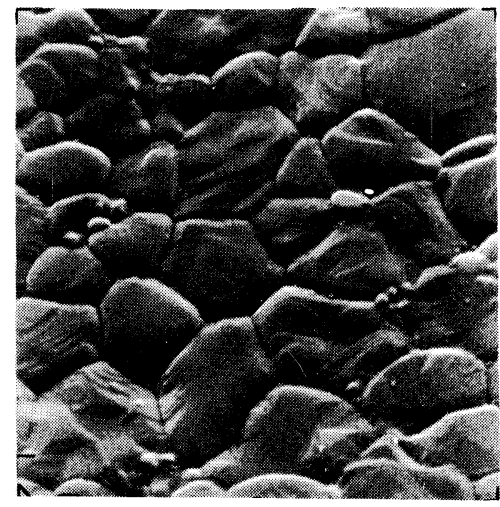

(b)

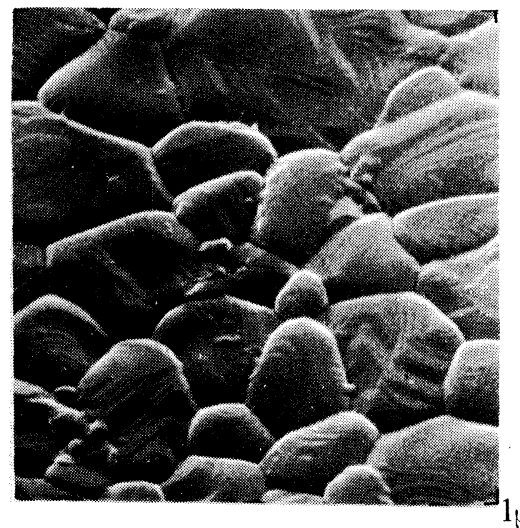

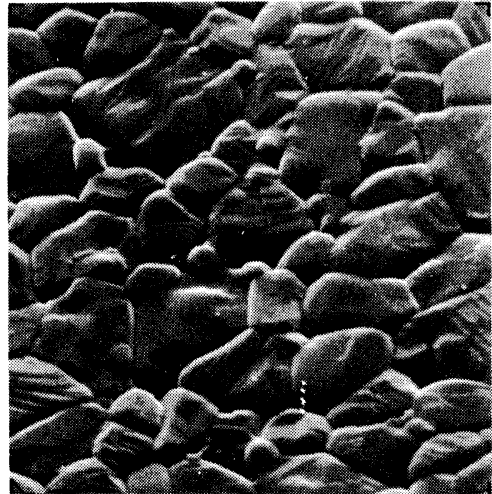

(c)

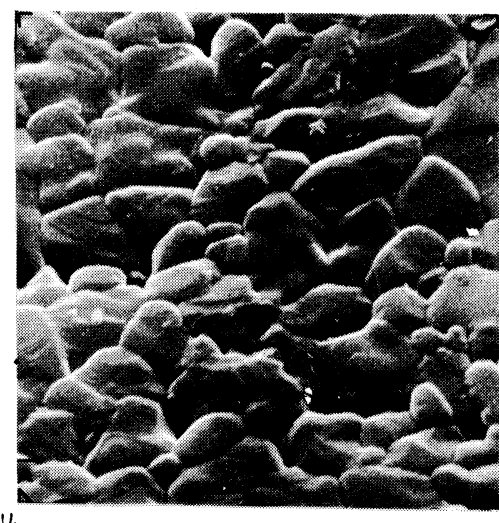

(d)

FIGURE 6 Scanning electron micrographs showing difference in microstructure of substrates fired at $1600^{\circ} \mathrm{C}, 2$ hours in hydrogen, 6(a) Gloss 75, 6(b) Gloss 65, 6(c) Gloss 58, 6(d) Gloss 52 .

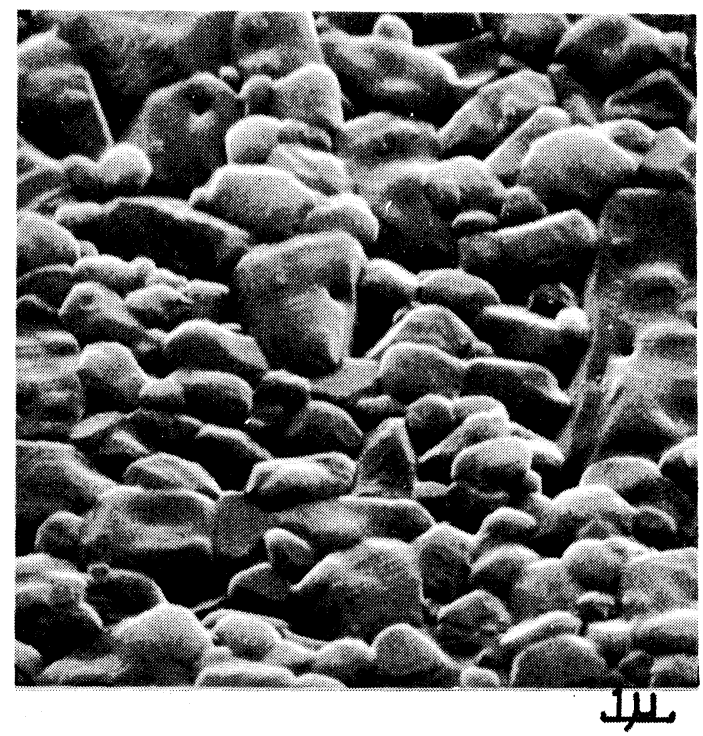

FIGURE 7 Typical microstructure of the $\mathrm{Al}_{2} \mathrm{O}_{3}-\mathrm{MgO}$ system substrate fired at $1600^{\circ} \mathrm{C}, 2$ hours in hydrogen. in a smoother surface. However, a more important factor is the green density. If this is as low as $2.0 \mathrm{~g} / \mathrm{cm}^{2}$, the substrate obtained after firing will show a low specific gravity, resulting in a rougher surface even when $0.025 \mathrm{wt} \% \mathrm{Cr}_{2} \mathrm{O}_{3}$ is included in the $\mathrm{Al}_{2} \mathrm{O}_{3}-\mathrm{MgO}-\mathrm{Cr}_{2} \mathrm{O}_{3}$ system.

Figure 8 shows an example of capacitor step stress reliability using the new substrate of $\mathrm{Al}_{2} \mathrm{O}_{3}-\mathrm{MgO}-\mathrm{Cr}_{2} \mathrm{O}_{3} .{ }^{9}$ In this experiment a tantalum-tantalum oxide $\left(\mathrm{Ta}-\mathrm{Ta}_{2} \mathrm{O}_{5}-\mathrm{Ni} \cdot \mathrm{Cr} \cdot \mathrm{Au}\right)$ film was applied to form capacitors on both the new alumina substrate without glazing (as-fired) and the commonly used glazed alumina substrate. The results show that the reliability of the capacitor on the unglazed new alumina is nearly similar to that on the glazed alumina.

\section{CONCLUSION}

The addition of $\mathrm{Cr}_{2} \mathrm{O}_{3}$ accelerates grain growth in the $\mathrm{Al}_{2} \mathrm{O}_{3}-\mathrm{MgO}-\mathrm{Cr}_{2} \mathrm{O}_{3}$ system. This is considered to be 


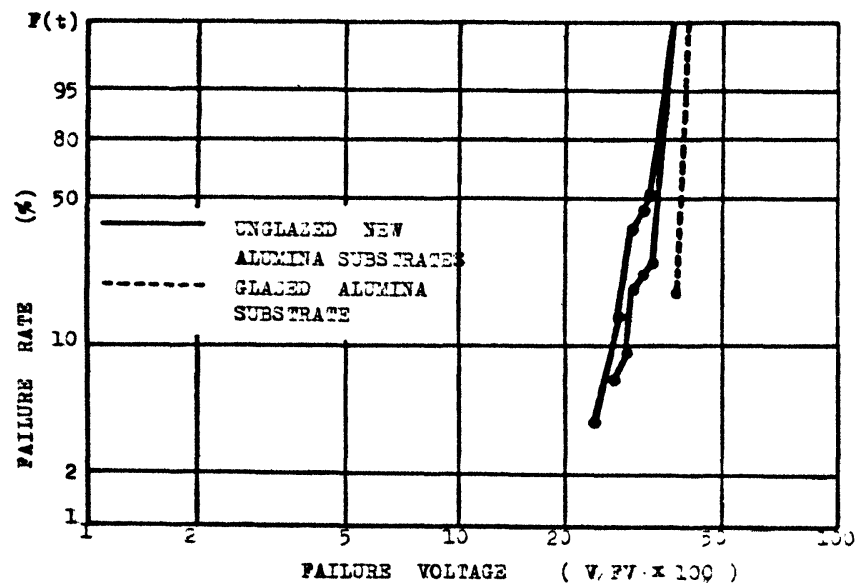

FIGURE 8 Weibull distribution of step stress failure; failure voltage $\mathrm{V}$ is indicated by the ratio, break down voltage $\mathrm{v} /$ forming voltage of $288 \mathrm{~V}$.

due to the diffusion of $\mathrm{Cr}_{2} \mathrm{O}_{3}$, which gives higher density than the $\mathrm{Al}_{2} \mathrm{O}_{3}-\mathrm{MgO}$ system. This results in a good surface smoothness. The smoothness is mainly dependent on the surface grain structure, which is a result of firing the green tape, which has high density and smoothness due to the tape casting.

\section{ACKNOWLEDGEMENT}

The authors would like to thank Dr. Satoshi Kojima, the Vice President of Fujitsu Laboratories Ltd., Dr. Hajime Sasaki, the Managing Director and Dr. Masatoshi Kubo, the Assistant Director for their encouragement. Also, they would like to thank Dr. Zenzo Henmi and Dr. Masashi Nakamura for their helpful suggestions.

\section{REFERENCES}

1. D. E. Peters and D. A. Rott, "Ceramic substrate for thin film circuits", IEEE International Convention 71C8, p. 566 (1971).
2. L. E. Ferreira, "Ceramic for microelectronics," IEEE International Convention, $71 C 8$ p. 560 (1971).

3. D. J. Shanefield and R. E. Mistler, "The manufacture of fine grained alumina substrates for thin films," Western Electric Eng., 15, 26 (1971).

4. M. D. Rigtoerink, "The present quality of ceramic electrical insulators," 71st Annual Meeting of The American Ceramic Society. Electronic Ceramics (Special Edition), (1969).

5. K. Niwa, K. Hashimoto and K. Murakawa, "Electrical properties and microstructure of alumina substrates," Fuiitsu Sci. Tech. J., 9, (1) (1973).

6. "Standard method of test for specular gloss," $A S T M$ D-523, (1967).

7. For example, R. M. Anderson and G. W. Neudeck, "Flatness and surface roughness of some common thin film substrate materials," Vac. Sci. and Technol., 8, 454 (1971).

8. R. F. Gruszka, R. E. Mistler and R. B. Runk, "Effect of various surface treatment on bend strength of high alumina substrates," Ceramic Bull., 49, 575 (1970).

9. K. Niwa, J. Nakamura, K. Murakawa and M. Nakamura, "New alumina substrate for hybrid integrated circuits" Proc. of 24th ECC, (1974). 

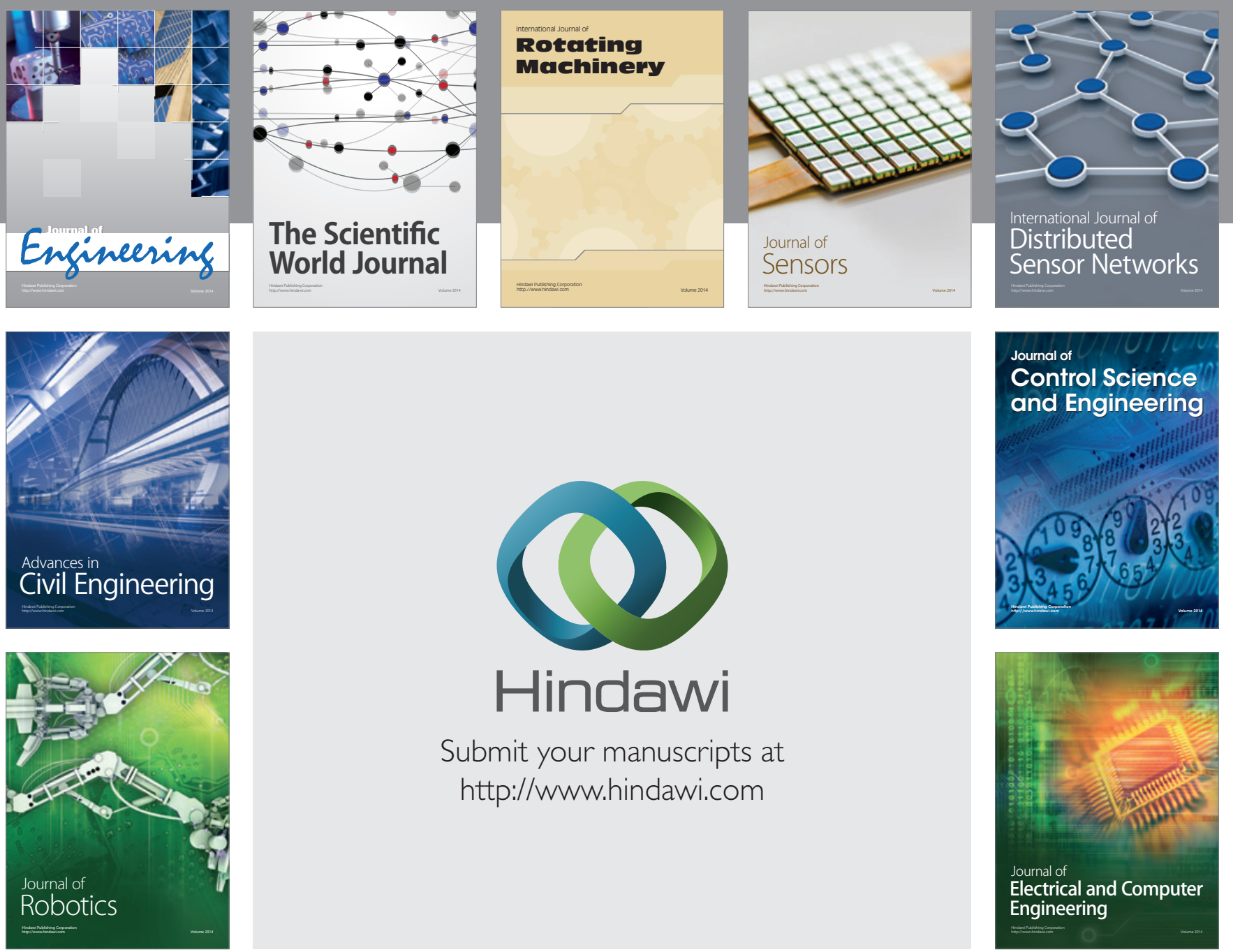

Submit your manuscripts at

http://www.hindawi.com
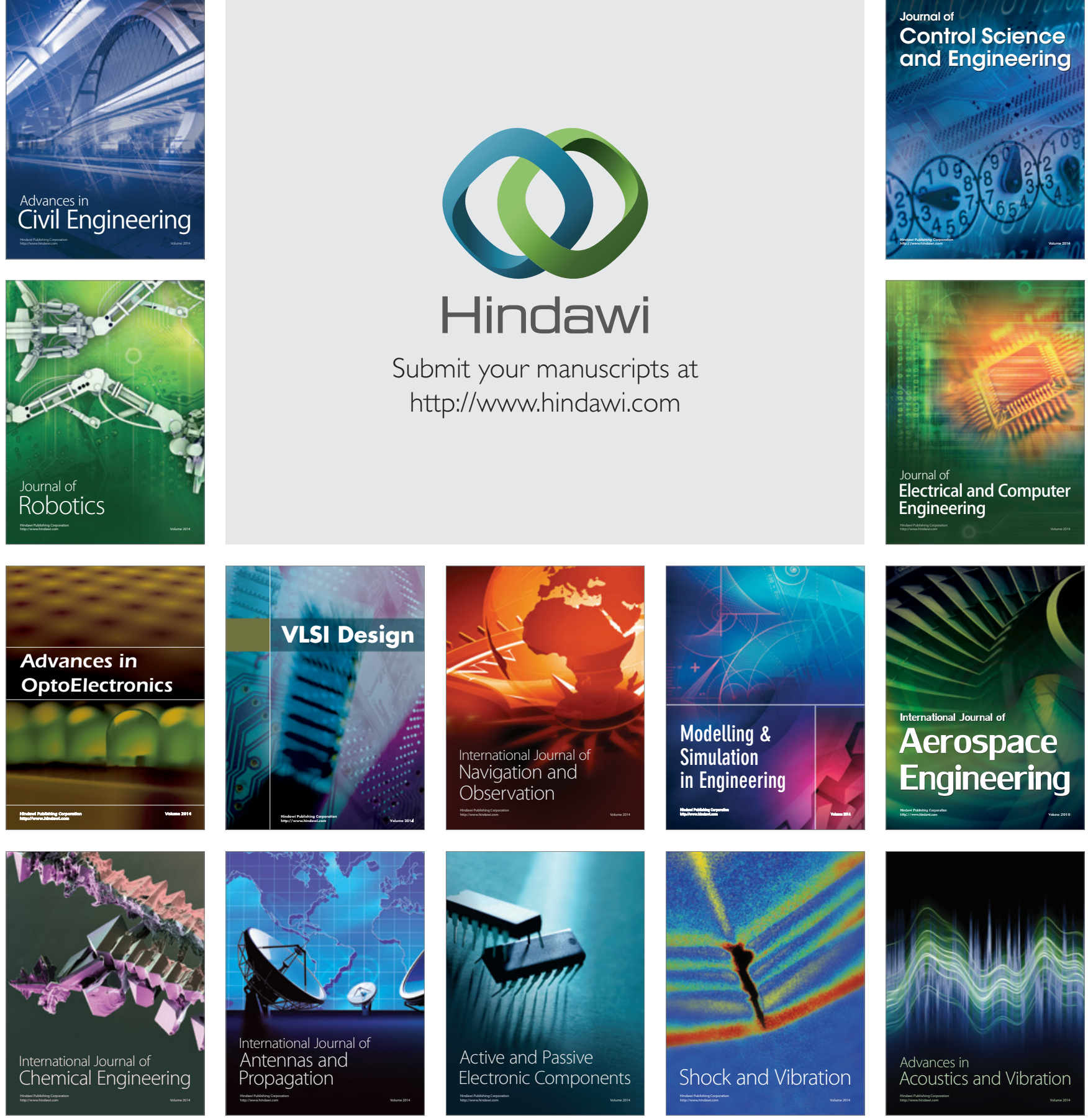